\title{
Mechanistic Insights into Indigo Reduction in Indigo Fermentation: A Voltammetric Study
}

\section{Kasumi NAKAGAWA, ${ }^{a}$ Michiki TAKEUCHI, ${ }^{b}$ Mayu KIKUCHI, ${ }^{c}$ Suzuna KIYOFUJI, ${ }^{c}$ Masami KUGO, ${ }^{c}$ Takaiku SAKAMOTO, ${ }^{\mathrm{a}, \mathrm{d}}$ Kenji KANO, ${ }^{\mathrm{c}, \mathrm{t}}$ Jun OGAWA, ${ }^{\mathrm{c}}$ and Eiji SAKURADANI ${ }^{\mathrm{a}, \mathrm{d}, *}$}

\author{
a Graduate School of Advanced Technology and Science, Tokushima University, 2-1 Minamijosanjima-cho, Tokushima 770-8513, Japan \\ b Industrial Microbiology, Graduate School of Agriculture, Kyoto University, Kitashirakawa Oiwake-cho, Sakyo-ku, Kyoto 606-8502, Japan \\ ' Division of Applied Life Sciences, Graduate School of Agriculture, Kyoto University, \\ Kitashirakawa Oiwake-cho, Sakyo-ku, Kyoto 606-8502, Japan \\ d Graduate School of Technology, Industrial and Social Sciences, Tokushima University, \\ 2-1 Minamijosanjima-cho, Tokushima 770-8513, Japan
}

* Corresponding author: sakuradani.eiji@tokushima-u.ac.jp

\section{ABSTRACT}

Indigo is one of the oldest natural blue dyes. Microorganisms and their enzymatic activities are deeply involved in the traditional indigo staining procedure. To elucidate the mechanism of the microbial indigo reduction, we directly performed cyclic voltammetry on alkaline fermenting dye suspensions. A pair of characteristic redox peaks of leuco-indigo was observed in a supernatant fluid of the fermenting dye suspension. On the other hand, it was found that the indigo/leuco-indigo redox couple mediated two-way microbially catalyzed oxidation and reduction in a sediment-rich suspension of the fermenting suspension. Acetaldehyde was supposed to be the electron donor and acceptor of the catalytic reactions. In order to verify the bioelectrocatalytic reaction, we isolated indigo-reducing bacterium $\mathrm{K} 2-3^{\prime}$ from the fermenting suspension, and the two-way bioelectrocatalysis was successfully restaged in a model system containing $\mathrm{K} 2-3^{\prime}$ and methyl viologen (as a soluble mediator instead of indigo) as well as acetaldehyde at $\mathrm{pH} 10$. C The Author(s) 2020. Published by ECSJ. This is an open access article distributed under the terms of the Creative Commons Attribution 4.0 License (CC BY,
http://creativecommons.org/licenses/by/4.0/), which permits unrestricted reuse of the work in any medium provided the original work is properly cited. [DOI:
10.5796/electrochemistry.20-00123].

Keywords : Indigo Reduction Mechanism, Acetaldehyde, Bioelectrocatalysis, Mediator

\section{Introduction}

Indigo was used as a pigment until around 1600. Around that period, Dutch sailors visited India and acquired technical knowledge of the fermentation method for indigo production, and indigo spread as a blue dye all over the world. ${ }^{1}$ Indigo has long been a widely known dye as a natural source of blue. Natural indigo production declined due to the development of artificial production in chemical industries, however, craftsmen who perform indigo dyeing are still very active in Japan. Japanese Aizome (indigo dyeing) is highly appreciated even in foreign countries and characterized by a deep blue color called "Japan blue".

Traditional indigo dyeing consists of two important steps: preparations of the dye material (called sukumo) and dye suspensions, both of which involve fermentation steps by microorganisms. Indigo plants (Polygonum tinctorium Lour., Syn: Persicaria tinctoria (Aiton) H. Gross) ${ }^{2}$ biosynthesize indican (indoxyl- $\beta$-D-glucoside) that is the precursor of indigo (Fig. 1A). Therefore, the first fermentation process is the transformation of indican into indigo for the preparation of indigo dye. The leaves are harvested and air-dried. Then, approximately three tons of dried leaves are mixed with the same amount of water and stacked to ca. $1 \mathrm{~m}$ in height (Fig. 1B). Once every 2 to 3 days, the leaves are mixed up and down with water for sufficient aeration (oxidative fermentation). The temperature reaches about $60^{\circ} \mathrm{C}$ due to the fermentation heat during the plant tissue decomposition. The microbial oxidative fermentation of the leaves proceeds under aerobic conditions and at an appropriate temperature with the sophisticated techniques of trained craftsmen. This operation takes

'Present address: Center for Advanced Science and Innovation, Kyoto University, Gokasho, Uji, Kyoto 611-0011, Japan up to 100 days to produce composted and fermented product called sukumo. The second fermentation process proceeds with sukumo in Aizome tanks that have been developed in Tokushima Prefecture, Shikoku, Japan. In the process of preparing the dye suspensions, insoluble indigo is microbially reduced into water-soluble leucoindigo (Fig. 1C). The reduction of indigo to leuco-indigo is catalyzed by microorganisms in highly alkaline suspensions ( $\mathrm{pH}$ 10.3-10.5), which are prepared with wood ash extract, slaked lime, wheat bran, Japanese sake, etc. ${ }^{3}$ When the leuco-indigo is adsorbed by clothing fibers and is exposed to the air, it is re-oxidized into indigo and is fixed to the fibers (Fig. 1D).

A number of indigo-reducing microorganisms were isolated from fermentation vats $^{3-15}$ and several enzymes involved in indigo reduction, such as an azoreductase, were characterized. ${ }^{16-19}$ However, little is known about the mechanism and the electron donor of the microbial indigo reduction as well as the significance of the alkali environment of the fermenting dye suspensions and the advantage of the addition of sake. The fermenting dye suspensions in which the indigo reduction takes place are highly complex regarding nutrients and microbial organisms, and thus the mechanism and the electron donor of the microbial indigo reduction in such environments remains unclear for long. It is considered that both indigo and leuco-indigo coexist in a fermenting dye suspension. Various analytical methods were reported for the quantitative and qualitative analyses of indigo dyes in aqueous solutions, for example, UV-Vis spectrophotometry with the addition of organic solvents such as dimethyl sulfoxide, dichloromethane, ${ }^{20,21}$ and redox titration using potassium hexacyanoferrate. ${ }^{22}$ However, when a part of the fermenting dye suspension is exposed to oxygen, leuco-indigo is immediately oxidized and converted into indigo. Spectroscopic methods are not applicable to detect or quantify indigo and leucoindigo in the fermenting dye suspension. Several electrochemical 

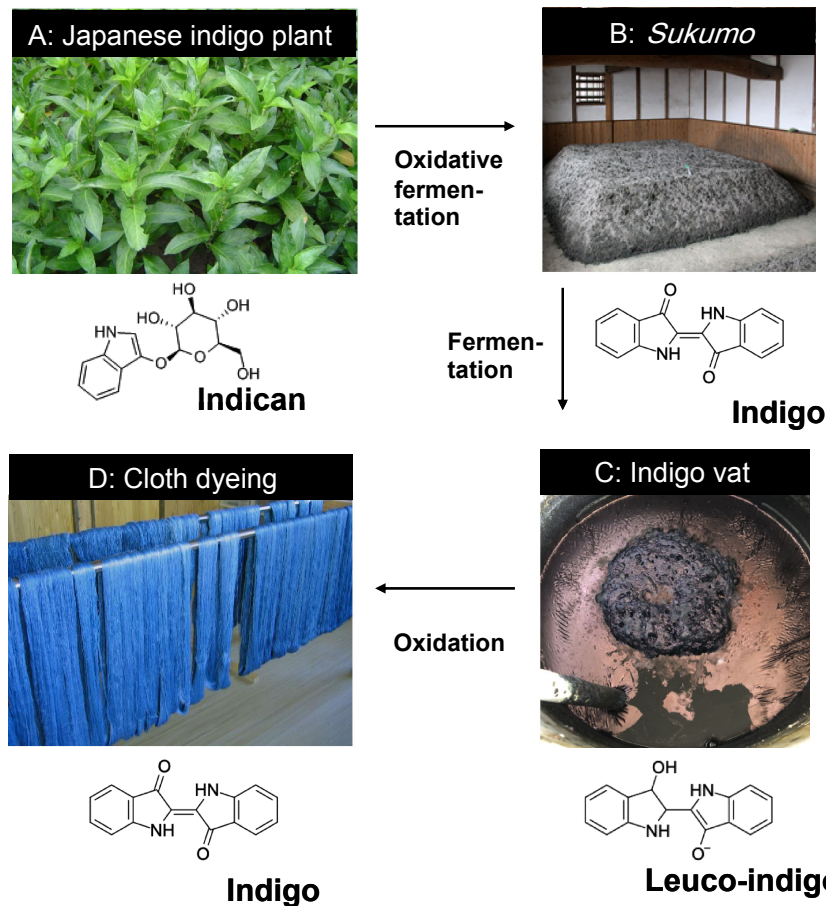

Indigo

Figure 1. Pictures of traditional indigo dyeing processes. (A) Japanese indigo plant leaves containing indican. The leaves are decomposed by aerobic microorganisms at suitable moisture contents and temperature controlled by skilled craftsmen for 100 days. (B) Sukumo: oxidatively fermented indigo plant leaves to generate indigo from indicant. (C) Top view of an indigo fermentation tank in which insoluble indigo is microbially reduced to leuco-indigo under anaerobic alkaline conditions ( $\mathrm{pH} \mathrm{10-12).}$ (D) Blue-colored fibers that adsorbed leuco-indigo in the indigo fermentation tank and were exposed to the air.

techniques were reported for ex-situ analyses of indigo. ${ }^{23-26}$ Therefore, in this study, we applied cyclic voltammetry to in-situ detection of leuco-indigo in fermenting dye suspension and attempted to get mechanistic insights into the mechanisms of microbial indigo reduction.

\section{Experimental}

\subsection{Preparation of indigo dye suspensions by fermentation}

The traditional Japanese fermentation procedure was performed on a laboratory scale. Wood ash $(500 \mathrm{~g})$ was mixed with $5 \mathrm{~L}$ of boiling water, and the wood charcoal was allowed to settle in the fluid overnight. The resultant supernatant (S1) was used as lye. The sediment was mixed with $10 \mathrm{~L}$ of boiling water, and the supernatant (S2) was prepared in the same manner as described above. Two $\mathrm{kg}$ of sukumo, which was purchased from Nii Seiaisyo (Tokushima, Japan), was well mixed with $1 \mathrm{~L}$ of boiling water in a $45-\mathrm{L}$ plastic bucket. Ten L of S2 and $100 \mathrm{ml}$ of Japanese sake (rice wine) were added, and the total volume was made up to $20 \mathrm{~L}$ with boiling water. The $\mathrm{pH}$ of the mixture was adjusted to $10-11$ with slaked lime. Two days later, $20 \mathrm{~g}$ of wheat bran was mixed with $1 \mathrm{~L}$ of boiling water, and the mixture was transferred to a fermentation vat. Two more days later, $5 \mathrm{~L}$ of $\mathrm{S} 1$ and $5 \mathrm{~L}$ of warm water $\left(30^{\circ} \mathrm{C}\right)$ were added.

The fermenting dye suspension in the fermentation vat was mixed with a bar once a day. The $\mathrm{pH}$, oxidation-reduction potential (ORP), and dissolved oxygen (DO) were measured using a D-75 (Horiba) electrode. The $\mathrm{pH}$ of the fermenting dye suspension decreased with the metabolite production by the microorganisms involved in the process. The $\mathrm{pH}$ of the fermenting dye suspension was kept in the range from 10 and 12 by adding slaked lime, and the staining intensity was occasionally checked by dipping a small portion of cotton textile into the dye suspension (Fig. S1).

For in-situ voltammetric measurements, $50 \mathrm{~mL}$ of the well-mixed fermenting dye suspension was sampled and left for 30 min under anaerobic conditions. $38 \mathrm{~mL}$ of the supernatant was removed and submitted to voltammetric analysis under anaerobic conditions. The remained sediment suspension $(12 \mathrm{~mL})$ was re-mixed and directly submitted to voltammetric analysis under anaerobic conditions. The supernatant and sediment-rich suspension reflect the situations of the upper and the bottom layers of the fermentation vat, respectively.

\subsection{Isolation of an indigo-reducing microorganism}

A drop of the suspension in the Aizome tank (fermenting tank) was inoculated into Alkaline Gifu Anaerobic Medium (Nissui Pharmaceutical, Japan) with $1 \%$ (w/v) $\mathrm{Na}_{2} \mathrm{CO}_{3}$ (alkali-GAM) and incubated again at $28^{\circ} \mathrm{C}$ under anaerobic conditions with Aneropack Kenki (Mitsubishi Gas Chemical Co., Inc., Tokyo, Japan). The culture broth was streaked on a $1.5 \%$ gellan gum plate of alkaliGAM and then incubated at $28^{\circ} \mathrm{C}$ under anaerobic conditions with Aneropack Kenki, and isolates were obtained. Indigo-reducing activity of the isolates was measured by the following method; the isolates were cultivated in $10 \mathrm{~mL}$ of alkali-GAM at $28^{\circ} \mathrm{C}$ for $16 \mathrm{~h}$ in an anaerobic chamber (Coy Laboratory Products Inc., Grass Lake, MI, USA), of which the atmosphere was $\mathrm{N}_{2}$ with $1-2 \% \mathrm{H}_{2}$. After cultivation, $10 \mathrm{~mL}$ of the culture broth was centrifuged at $1500 \mathrm{~g}$ for $10 \mathrm{~min}$. Ten $\mathrm{mL}$ of indigo suspension (the total amount per volume corresponding to ca. $\left.1 \mathrm{mM}\left(\mathrm{M} \equiv \mathrm{mol} \mathrm{L}^{-1}\right)\right)$ in $20 \mathrm{mM}$ sodium carbonate buffer ( $\mathrm{pH}$ 10.0) was added to the harvested cells, followed by incubation at $28^{\circ} \mathrm{C}$ for $16 \mathrm{~h}$ in an anaerobic chamber; during the cultivation, microbial reduction of indigo proceeded with some electron donors contained in the harvested cell paste, possible candidates being some microbial metabolites such as acetaldehyde. After the reaction, the reaction mixture was centrifuged at $1500 \mathrm{~g}$ for $10 \mathrm{~min}$. The supernatant containing leuco-indigo was exposed to the air, and the optical density at $660 \mathrm{~nm}\left(\mathrm{OD}_{660}\right)$ of the resulting indigo was measured. The increase in $\mathrm{OD}_{660}$ compared to that of the brank (without microorganisms) was regarded as a measure of the indigo-reducing activity. The isolate showing the highest indigoreducing activity was obtained and named $\mathrm{K} 2-3^{\prime}$. As the result of 16S rRNA analysis, K2-3' was identified as Enterococcus sp., with a similarity of $100 \%$. The nucleotide sequence reported in this study was deposited in the DDBJ database under DDBJ/EMBL/GenBank accession number LC586216.

\subsection{Bioelectrochemical characterization of fermentation suspensions}

Electrochemical measurements were carried out with an ALS1205C voltammetric analyzer at room temperature (ca. $25^{\circ} \mathrm{C}$ ) under a nitrogen atmosphere. The working electrode was a glassy carbon disk electrode (GCE, $3 \mathrm{~mm}$ in diameter; BAS, Tokyo, Japan). The GCE was polished with $0.05 \mu \mathrm{m}$ alumina powder and washed with distilled water. The reference electrode was a handmade $\mathrm{Ag}|\mathrm{AgCl}| \mathrm{sat} . \mathrm{KCl}$ electrode. The counter electrode was $5 \mathrm{~cm}$ Pt-wire (Nilaco, Tokyo, Japan). The electrode potential in this paper is referred to the reference electrode unless otherwise stated.

To maintain anaerobic conditions, the electrochemical cells were continuously purged with $\mathrm{N}_{2}$ gas. Cyclic voltammetry was carried out at a scan rate of $10 \mathrm{mV} \mathrm{s}^{-1}$ under quiescent conditions.

\subsection{Bioelectrocatalytic activity of K2-3' against acetaldehyde}

Strain $\mathrm{K} 2-3^{\prime}$ was inoculated into five tubes containing $10 \mathrm{~mL}$ of alkali-GAM and incubated at $37^{\circ} \mathrm{C}$ for $18 \mathrm{~h}$ under anaerobic conditions with Anaeropack Kenki (Mitsubishi Gas Chemical Co., Inc., Japan). After the cultivation, K2-3' was harvested by centrifugation at $1500 \mathrm{~g}$ for $10 \mathrm{~min}$. The cells were suspended in $100 \mathrm{mM}$ sodium carbonate buffer $(\mathrm{pH} 10.0)$ and then collected by 
centrifugation. The collected cells were washed twice with the $100 \mathrm{mM}$ sodium carbonate buffer ( $\mathrm{pH} 10.0)$. The reaction mixture contained the washed cells (ca. $0.7 \mathrm{~g} \mathrm{~mL}^{-1}$ ), $0.24 \mathrm{mg} \mathrm{mL}^{-1}$ methyl viologen dichloride (1,1'-dimethyl-4,4'-bipyridinium dichloride) $n$-hydrate (Wako Pure Chemicals, Osaka, Japan), and $9.3 \mathrm{mM}$ acetaldehyde (Wako Pure Chemicals, Osaka, Japan) in the $100 \mathrm{mM}$ sodium carbonate buffer ( $\mathrm{pH} 10.0$ ). Electrochemical measurements were carried out before and after adding acetaldehyde solution.

\section{Results and Discussion}

\subsection{Voltammetric behavior of the indigo fermenting dye suspensions}

In order to obtain insights into the mechanism of the indigo fermentation, cyclic voltammetric measurements were done to the supernatant and the sediment-rich suspension of the indigo fermenting dye suspension. The supernatant gave a couple of characteristic peaks with the peak potentials of $-0.51 \mathrm{~V}$ and $-0.71 \mathrm{~V}$ (Fig. 2A). We expected that the anodic and cathodic peaks could be assigned to the electrochemical oxidation of leuco-indigo and re-reduction of indigo, respectively. To confirm this, cyclic voltammograms were measured for a chemically reduced indigo

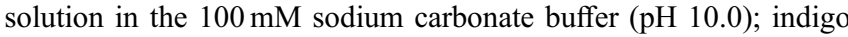
was reduced with sodium hydrosulfite under anaerobic conditions. As shown in Fig. 2B, the cyclic voltammogram of leuco-indigo was very similar to that of the supernatant of the indigo dye suspension (Fig. 2A). These results verify our expectation. The small peak height of the cathodic wave compared with the anodic one seems to be due to partial precipitation of electrochemically generated indigo;

$$
\text { leuco-indigo }{ }^{-} \rightleftarrows \text { indigo }(\downarrow)+2 \mathrm{e}^{-}+\mathrm{H}^{+},
$$

where leuco-indigo exists as a deprotonated monoanion in an alkaline solution, because the $\mathrm{p} K_{\mathrm{a}}$ values of the hydroxy groups are 8.0 and 12.7. ${ }^{27}$ The formal potential can be judged to be close to or slightly more positive than $-0.61 \mathrm{~V}$ (as the midpoint potential of the voltammogram in Fig. 2A). The anodic peak height can be utilized as a measure of the concentration of leuco-indigo in fermenting dye suspensions. The in-situ voltammetric method was also applied to direct monitoring of leuco-indigo in the fermentation vats during the fermenting process. Details will be reported elsewhere.

In contrast, the sediment-rich suspension showed steady-state catalytic waves in cyclic voltammetry, as shown in Fig. 3. The concentration of any soluble electron donors and acceptors (and extracellular soluble enzymes if any) in sediment-rich suspension should be equal to that in the supernatant, but the population of microbial organisms in sediment-rich suspension is much higher than that in the suspension. Therefore, it can be concluded that the electrocatalytic reactions are catalyzed by the microbial organisms in the sediments.

Two steady-state oxidation waves were observed with half-wave potentials of $-0.56 \mathrm{~V}$ and $-0.29 \mathrm{~V}$. Since the half-wave potential of the negative-side catalytic oxidation wave was close to the peak potential of leuco-indigo (Fig. 2A), the wave is characterized as indigo/leuco-indigo-mediated bioelectrochemical catalytic oxidation of a reductant $\left(\operatorname{Red}_{1}\right)$ in the fermenting dye suspension. The catalyst is a redox enzyme(s) (redox enzyme 1) in the microorganism;

$$
\operatorname{Red}_{1}+\text { indigo } \stackrel{\text { redox enzyme } 1}{\longrightarrow} \mathrm{Ox}_{1}+\text { leuco-indigo }
$$

The enzymatically generated leuco-indigo is oxidized at the electrode (Eq. (1)). From the thermodynamic viewpoint (that is, to satisfy the down-hill condition in the electron transfer in Eq. (2)), the formal potential of the $\mathrm{Ox}_{1} / \operatorname{Red}_{1}$ redox couple should be more negative than that of the indigo/leuco-indigo couple (ca. $-0.6 \mathrm{~V}$ ). Table $1^{28}$ summarizes the formal potentials of some redox
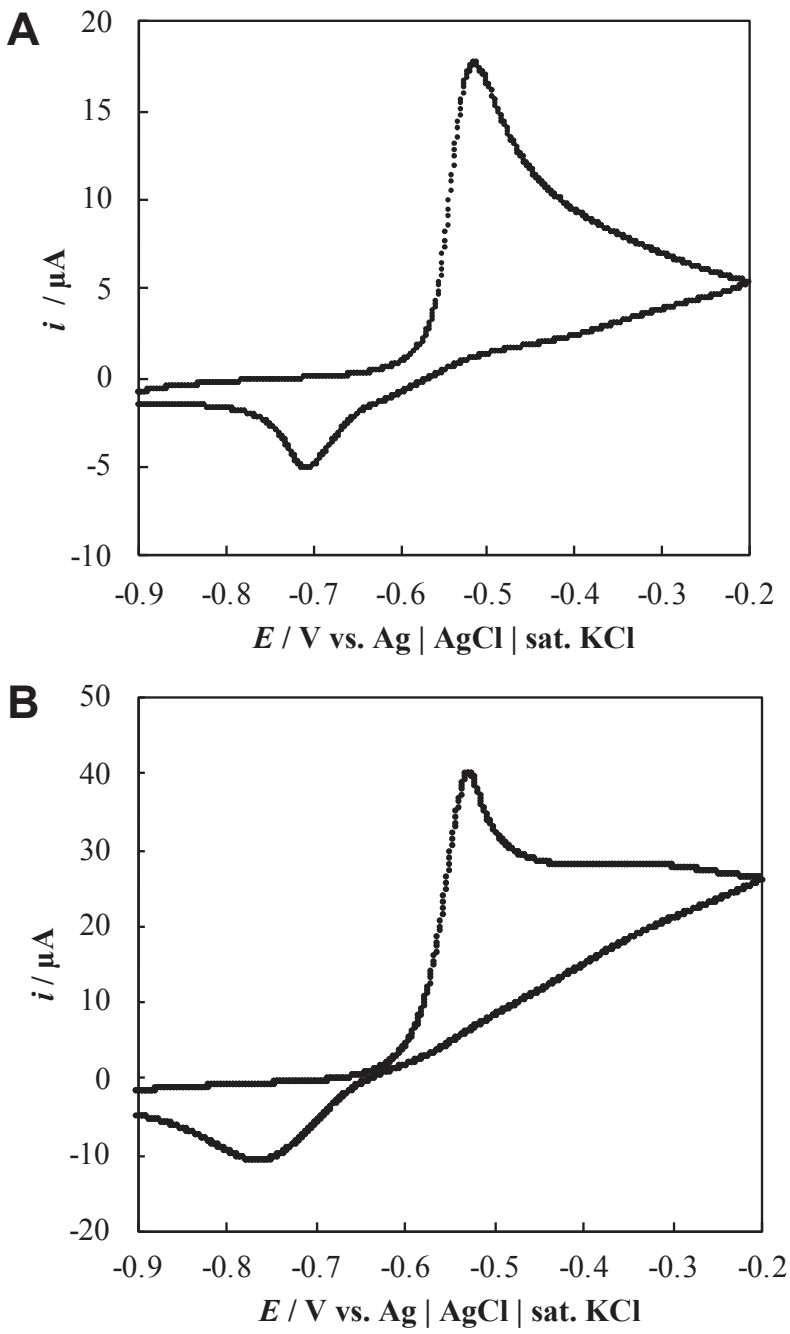

Figure 2. Cyclic voltammograms recorded at a scan rate $(v)$ of $0.01 \mathrm{~V} \mathrm{~s}^{-1}$ with a bare GC electrode under a complete nitrogen atmosphere in (A) the supernatant of the fermenting dye suspension ( $\mathrm{pH}$ 10.65), and (B) a chemically reduced leuco-indigo solution (sodium dithionite $\left(\mathrm{Na}_{2} \mathrm{~S}_{2} \mathrm{O}_{4}\right)$ ) in $100 \mathrm{mM}$ carbonate buffer (pH 10.0)

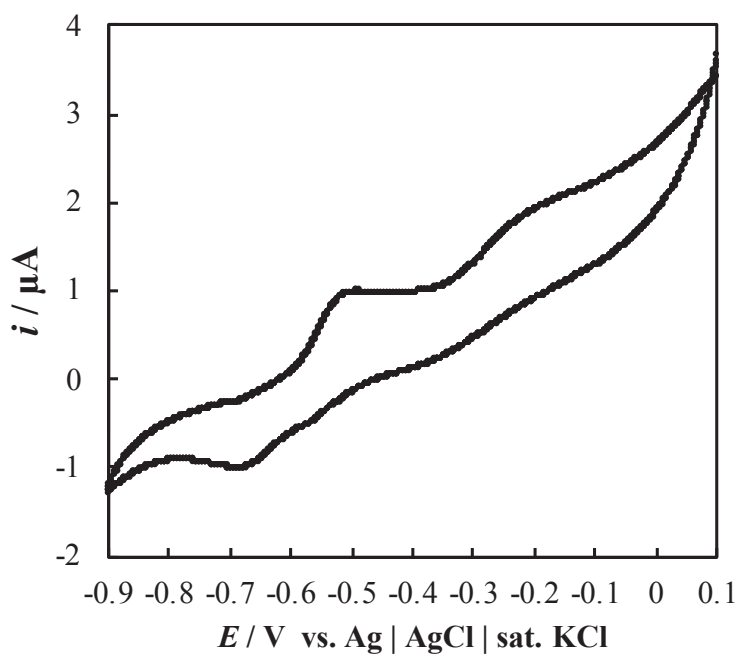

Figure 3. Cyclic voltammograms recorded in a sediment-rich suspension of the fermenting dye suspension at $v=0.01 \mathrm{~V} \mathrm{~s}^{-1}$ with a bare GC electrode under a nitrogen atmosphere. 
Table 1. Formal potentials of half-reactions of some redox compounds considered. ${ }^{\mathrm{a}}$

\begin{tabular}{|c|c|c|c|c|}
\hline \multirow{3}{*}{ Half-Reaction } & \multicolumn{4}{|c|}{$E^{\circ \prime}$} \\
\hline & \multirow{2}{*}{$\frac{\text { /V vs. SHE }}{(\mathrm{pH} 7)}$} & \multicolumn{3}{|c|}{ /V vs. $\mathrm{Ag} / \mathrm{AgCl} /$ sat. $\mathrm{KCl}$} \\
\hline & & $(\mathrm{pH} 7)$ & $(\mathrm{pH} 10)$ & $(\mathrm{pH} 12)$ \\
\hline Acetaldehyde $+2 \mathrm{H}^{+}+2 \mathrm{e}^{-} \rightleftharpoons$ Ethanol & -0.197 & -0.394 & -0.571 & -0.689 \\
\hline $\mathrm{FAD}+2 \mathrm{H}^{+}+2 \mathrm{e}^{-} \rightleftharpoons \mathrm{FADH}_{2}($ free coenzyme $)$ & -0.219 & -0.416 & -0.593 & -0.711 \\
\hline $\mathrm{NAD}^{+}+\mathrm{H}^{+}+2 \mathrm{e}^{-} \rightleftharpoons \mathrm{NADH}$ & -0.315 & -0.512 & -0.601 & -0.660 \\
\hline $2 \mathrm{H}^{+}+2 \mathrm{e}^{-} \rightleftharpoons \mathrm{H}_{2}$ & -0.421 & -0.618 & -0.795 & -0.913 \\
\hline $\mathrm{MV}^{2+}+\mathrm{e}^{-} \rightleftharpoons \mathrm{MV}^{\bullet+}$ & -0.440 & -0.637 & -0.637 & -0.637 \\
\hline $\mathrm{CO}_{2}(\mathrm{~g})+\mathrm{H}^{+}+2 \mathrm{e}^{-} \rightleftharpoons$ Formate & -0.443 & -0.640 & -0.728 & -0.788 \\
\hline Acetate $^{-}+3 \mathrm{H}^{+}+2 \mathrm{e}^{-} \rightleftharpoons$ Acetaldehyde $+\mathrm{H}_{2} \mathrm{O}$ & -0.581 & -0.778 & -1.044 & -1.221 \\
\hline
\end{tabular}

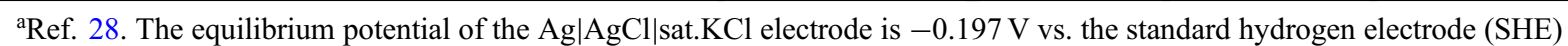
at $25^{\circ} \mathrm{C}$.

compounds considered in this research. The most likely candidate for $\operatorname{Red}_{1}$ is acetaldehyde in Table 1 (bottom), and then the oxidized product $\mathrm{Ox}_{1}$ is assigned to acetate. Acetaldehyde is possibly supplied by enzymatic oxidation of ethanol, which is supplied by alcohol fermentation from glucose (and some other sugars) or often by addition of sake in the practical fermentation process. The sour aroma during the dye fermentation in the fermentation vat is reasonably ascribed to acetic acid generated by the reaction (Eq. (2)). Hydrogen $\left(\mathrm{H}_{2}\right)$ might be one of candidates for $\mathrm{Red}_{1}$, but $\mathrm{H}_{2}$ cannot exist stably in the fermenting dye suspension. Formate might not be ruled out as one of candidates for $\operatorname{Red}_{2}$ from the thermodynamic view point (Table 1), but we will focus on acetaldehyde as $\operatorname{Red}_{2}$ in this paper and continue our research on formate also in future. A similar reaction proceeds in the positiveside catalytic oxidation wave (Fig. 3). Unfortunately, since a (noncatalytic) oxidation peak was not detected around $-0.29 \mathrm{~V}$ in the supernatant of the fermenting dye suspension (Fig. 2A), the redox compound that mediated the bioelectrocatalytic oxidations seem to exist only in the sediment-rich suspension.

On the other hand, the peak-shaped reduction wave of indigo (Fig. 2A) changed into a steady-state catalytic reduction wave with a half-wave potential of $-0.64 \mathrm{~V}$ in the sediment-rich suspension (Fig. 3). The wave is characterized as indigo/leuco-indigo-mediated bioelectrochemical catalytic reduction of an oxidant $\left(\mathrm{Ox}_{2}\right)$ in the suspension, but the catalytic reaction rate is not so high. The catalyst is a redox enzyme(s) (redox enzyme 2) in the microorganism;

$$
\mathrm{Ox}_{2}+\text { leuco-indigo } \stackrel{\text { redox enzyme } 2}{\longrightarrow} \operatorname{Red}_{2}+\text { indigo. }
$$

The enzymatically generated indigo is reduced at the electrode (Eq. (1)). From the thermodynamic viewpoint, the formal potential of the $\mathrm{Ox}_{2} / \mathrm{Red}_{2}$ redox couple will be more positive than that of the indigo/leuco-indigo couple (ca. $-0.6 \mathrm{~V}$ ). The most likely candidate for $\mathrm{Ox}_{2}$ is also acetaldehyde in Table 1 (top), and the reduced product $\operatorname{Red}_{2}$ can be assigned to ethanol.

\subsection{Two-way bioelectrocatalysis for acetaldehyde in a model system containing $\mathrm{K} 2-3^{\prime}$ and methyl viologen}

In order to verify our consideration described in Section 3.1, we constructed a model system for the indigo fermenting suspension. Since the solubility of indigo is very low, we used water-soluble methyl viologen $\left(\mathrm{MV}^{2+}\right)$ in place of indigo as a mediator of the bioelectrocatalysis, since the formal potential of the $\mathrm{MV}^{2+} / \mathrm{MV}^{*+}$ couple is close to that of indigo in alkaline solutions (Table 1);

$$
\mathrm{MV}^{2+}+\mathrm{e}^{-} \rightleftarrows \mathrm{MV}^{\bullet+} \text {. }
$$

We utilized bacterium $\mathrm{K} 2-3^{\prime}$ as a catalysis that was isolated from the fermenting dye suspension and exhibited the reduction activity toward indigo.
Voltammetric studies were performed in $100 \mathrm{mM}$ sodium carbonate buffer ( $\mathrm{pH} 10.0)$ in the presence of $0.3 \mathrm{~g}$ of wet cells of $\mathrm{K}^{2}-3^{\prime}$ (per $300 \mu \mathrm{L}$ ) using $\mathrm{MV}^{2+} / \mathrm{MV}^{*+}(0.24 \mathrm{mg} / \mathrm{mL})$ as a mediator. $\mathrm{MV}^{2+}$ gave a couple of non-catalytic reversible redox waves in the absence of acetaldehyde even in the presence of the K2-3' cells (Fig. 4A, curve red). The midpoint potential $(-0.64 \mathrm{~V})$ is in good agreement with that in the literature $(-0.637 \mathrm{~V}$, Table 1$)$.

When acetaldehyde $(9.3 \mathrm{mM})$ was added to the model system, the peak-shaped wave changed into a steady-state sigmoidal one due to bioelectrocatalysis of the oxidation and reduction of acetaldehyde. In the catalytic reaction, the strain $\mathrm{K} 2-3^{\prime}$ cells and the $\mathrm{MV}^{2+} / \mathrm{MV}^{\bullet+}$ couple acted as a catalyst and a mediator, respectively. The data clearly support our idea that acetaldehyde can act as both an electron donor for $\mathrm{MV}^{2+}$ and an acceptor for $\mathrm{MV}^{\bullet+} . \mathrm{MV}^{2+}$ and $\mathrm{MV}^{\bullet+}$ were replaced with indigo and leuco-indigo, respectively, in the indigo fermenting suspension. Therefore, we can safely conclude that the microbial reduction of indigo in fermenting dye suspensions is catalyzed by an acetaldehyde dehydrogenase (Eq. (2), in which $\operatorname{Red}_{1}$ is acetaldehyde and $\mathrm{Ox}_{1}$ is acetate). We suppose that the enzyme (redox enzyme 1 in Eq. (2)) may be a molybdopterin enzyme. Further study is also required for the production of acetaldehyde under such alkaline conditions of the fermenting due suspension.

An NADH-dependent indigo-reducing enzyme was reported. ${ }^{18}$ Since the formal potential of the $\mathrm{NAD}^{+} / \mathrm{NADH}$ couple is $-0.601 \mathrm{~V}$ at $\mathrm{pH}$ 10, as shown in Table 1, NADH can barely act as an electron donor to indigo under the condition. When the $\mathrm{pH}$ is above 10 , NADH becomes more difficult to act as an electron donor to indigo.

On the other hand, this work has also raised the possibility that acetaldehyde is reduced back to ethanol by redox enzyme 2 in Eq. (3), most probably an NAD(P)-independent molybdopterin alcohol dehydrogenase. ${ }^{29}$ Especially when we used $\mathrm{MV}^{\bullet+}$ as an electron donor, strong acetaldehyde-reducing activity (as a reverse reaction of alcohol dehydrogenase) was observed compared with leuco-indigo (Figs. 3 and $4 \mathrm{~A}$ ). The reason is that the formal potential of the $\mathrm{MV}^{2+} / \mathrm{MV}^{*+}$ couple is more negative than that of indigo.

However, the enzymatic leuco-indigo oxidizing reaction with acetaldehyde (Eq. (3) in which $\mathrm{Ox}_{2}$ and $\mathrm{Red}_{2}$ are acetaldehyde and ethanol, respectively) is not convenient for the indigo reduction in the dye fermentation. Here, we should consider the $\mathrm{pH}$ dependence of the formal potential $\left(E^{\circ \prime}\right)$ as given by:

$$
E^{\circ \prime} \mathrm{pH}_{2}=E^{\circ \prime}{ }_{\mathrm{pH}}-2.303 \frac{m R T}{n F}\left(\mathrm{pH}_{2}-\mathrm{pH}_{1}\right),
$$

where $m$ and $n$ are the numbers of protons and electrons, respectively, $R, T$, and $F$ being the gas constant, absolute temperature, and Faraday constant, respectively. The $m$ values of the acetate/acetaldehyde, acetaldehyde/ethanol, and indigo/leuco-in- 
A

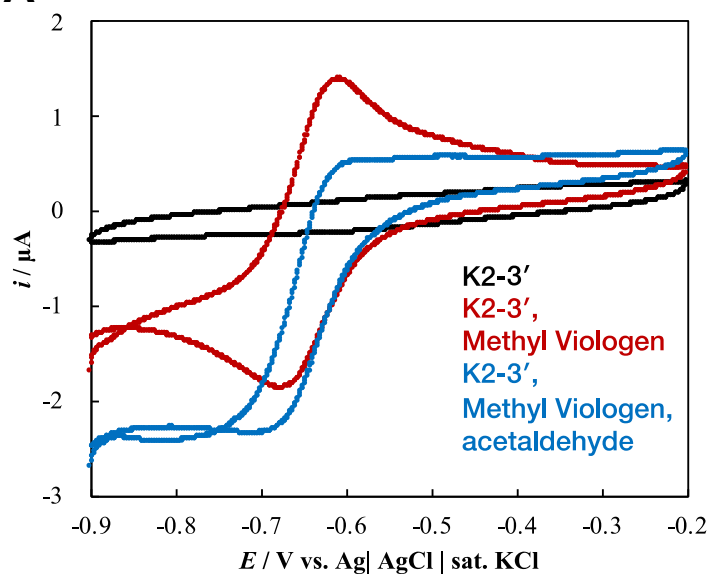

B

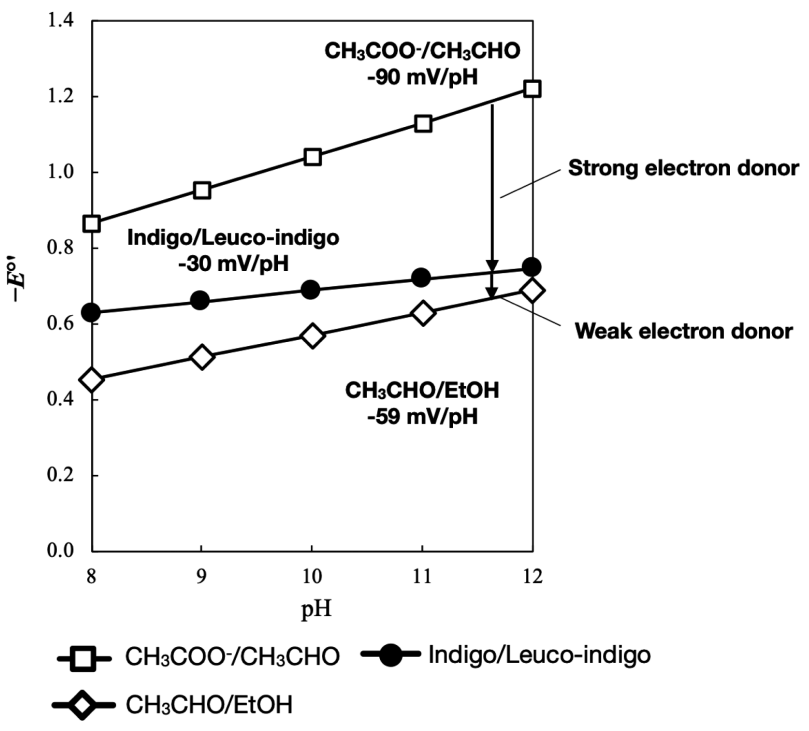

Figure 4. (A) Cyclic voltammograms of a model bioelectrochemical-system containing the $\mathrm{K} 2-3^{\prime}$ strain as an electrocatalyst and $\mathrm{MV}^{2+}$ as a mediator in $100 \mathrm{mM}$ sodium carbonate buffer $(\mathrm{pH} 10.0)$. (Black) The K2-3' strain alone, (red) after the addition of $10 \mathrm{mM}$ $\mathrm{MV}^{2+}$, and (blue) after further addition of $100 \mathrm{mM}$ acetaldehyde. All experiments were performed with a bare GC electrode at $v=$ $10 \mathrm{mV} \mathrm{s}^{-1}$ under a nitrogen atmosphere. (B) The $\mathrm{pH}$-dependence of the formal potentials of (open squares) acetate/acetaldehyde, (circles) indigo/leuco-indigo, and (open diamonds) acetaldehyde/ethanol. digo redox couples are 3 (Eq. (6)), 2 (Eq. (7)), and 1 (Eq. (1)), respectively, in the two-electron transfers $(n=2)$.

$$
\begin{aligned}
& \mathrm{CH}_{3} \mathrm{COO}^{-}+2 \mathrm{e}^{-}+3 \mathrm{H}^{+} \rightleftarrows \mathrm{CH}_{3} \mathrm{CHO}+\mathrm{H}_{2} \mathrm{O}, \\
& \mathrm{CH}_{3} \mathrm{CHO}+2 \mathrm{e}^{-}+2 \mathrm{H}^{+} \rightleftarrows \mathrm{CH}_{3} \mathrm{CH}_{2} \mathrm{OH} .
\end{aligned}
$$

Therefore, under highly alkaline conditions, acetaldehyde behaves as a very strong electron donor (to indigo). On the other hand, its electron-accepting ability (from leuco-indigo) is drastically weakened (Fig. 4B), and then the anticipated re-oxidation of leucoindigo with acetaldehyde would be minimized at strongly alkaline conditions. These redox properties of the participants appear to be the keystone to explanation of the significance of alkaline conditions in indigo dye fermentation.

\section{Conclusion}

Leuco-indigo was directly detected by cyclic voltammetry in the supernatant of the fermenting dye suspension. The voltammetric experiments in the sediment-rich (that is, microbe-rich) suspension of the fermenting dye suspension showed steady-state catalytic oxidation and reduction waves. A model bioelectrocatalytic system involving indigo-reducing bacterium strain $\mathrm{K} 2-3^{\prime}$ and $\mathrm{MV}^{2+}$ as an electrocatalyst and a mediator, respectively, confirmed that acetaldehyde can both donate electrons to $\mathrm{MV}^{2+}$ and accept electrons from $\mathrm{MV}^{*+}$; the reactions were catalyzed by redox enzymes in the $\mathrm{K} 2-3^{\prime}$ strain. We can propose a mechanism for indigo fermentation as shown in Scheme 1. Indigo in sukumo is reduced by acetaldehyde with an (NAD-independent) acetaldehyde dehydrogenase to generate leuco-indigo and acetate predominantly in the bottom of the fermentation vat. Acetaldehyde can be supplied by alcohol fermentation. Therefore, the sour aroma of acetic acid and the addition of sake in the practical fermenting process are very reasonable. Leuco-indigo is auto-oxidized by $\mathrm{O}_{2}$ into indigo especially on the surface of the fermenting dye suspension. In addition, part of leuco-indigo may be re-oxidized into indigo by acetaldehyde as the reverse-reaction of alcohol dehydrogenase. In order to weaken the electron accepting ability (and also to strengthen the electron donating ability) of acetaldehyde, it is very important to keep the strongly alkaline conditions during the dye fermentation. This situation is strictly practiced in the practical fermenting process. We are attempting to isolate and clone the enzyme(s) participating in the fermenting process.

\section{Supporting Information}

The Supporting Information is available on the website at DOI: https://doi.org/10.5796/electrochemistry.20-00123.

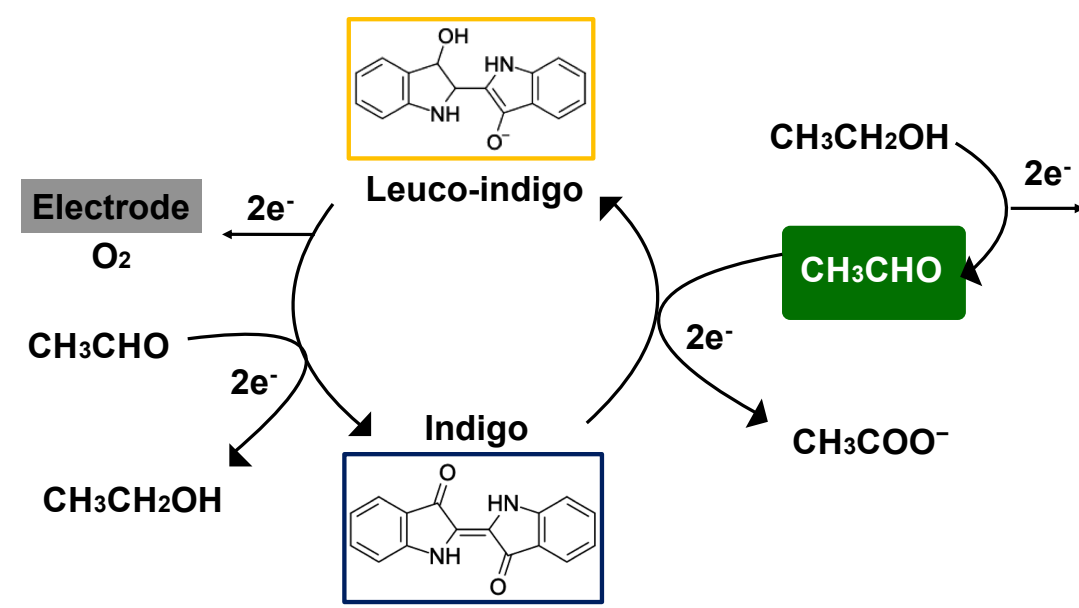

Scheme 1. Proposed redox reactions of indigo and leuco-indigo occurring in indigo dye fermenting suspensions. 


\section{Acknowledgments}

We thank Associate Professor N. Ariuchi (Shikoku University) and Mr. O. Nii (Nii Seiaisho) for teaching us the preparation procedure for indigo dye fermentation. We thank Professor M. Yasuzawa and Associate Professor M. Kurashina (Tokushima University) for their cooperation. This work was supported by a Grant-in-Aid for JSPS Fellows (19J14020, to K. N.), and partially supported by JSPS KAKENHI Grant Numbers 16K14884 and 20K15432 to J. O. and M. T., respectively.

\section{References}

1. R. J. H. Clark, C. J. Cooksey, M. A. M. Daniels, and R. Withnall, Endeavour, 17, $191(1993)$

2. Y. Minami, H. Takao, T. Kanafuji, K. Miura, M. Kondo, I. Hara-Nishimura, M. Nishimura, and H. Matsubara, Plant Cell Physiol., 38, 1069 (1997).

3. K. Aino, T. Narihiro, K. Minamida, Y. Kamagata, K. Yoshimune, and I. Yumoto, FEMS Microbiol. Ecol., 74, 174 (2010).

4. I. Yumoto, K. Hirota, Y. Nodasaka, Y. Yokota, T. Hoshino, and K. Nakajima, Int. J. Syst. Evol. Microbiol., 54, 2379 (2004)

5. K. Nakajima, K. Hirota, K. Y. Nodasaka, and I. Yumoto, Int. J. Syst. Evol. Microbiol., 55, 1525 (2005).

6. I. Yumoto, K. Hirota, Y. Nodasaka, Y. Tokiwa, and K. Nakajima, Int. J. Syst. Evol. Microbiol., 58, 901 (2008).

7. K. Hirota, K. Aino, and I. Yumoto, Int. J. Syst. Evol. Microbiol., 63, 4303 (2013).

8. K. Hirota, K. Aino, Y. Nodasaka, and I. Yumoto, Int. J. Syst. Evol. Microbiol., 63, 1437 (2013).

9. K. Hirota, K. Aino, Y. Nodasaka, N. Morita, and I. Yumoto, Int. J. Syst. Evol. Microbiol., 63, 464 (2013)

10. K. Hirota, T. Okamoto, H. Matsuyama, and I. Yumoto, Int. J. Syst. Evol.
Microbiol., 66, 4650 (2016).

11. K. Hirota, K. Aino, and I. Yumoto, Int. J. Syst. Evol. Microbiol., 66, 2247 (2016).

12. K. Hirota, M. Nishita, H. Matsuyama, and I. Yumoto, Int. J. Syst. Evol. Microbiol., 67, 4050 (2017).

13. M. Nishita, K. Hirota, H. Matsuyama, and I. Yumoto, World J. Microbiol. Biotechnol., 33, 133 (2017).

14. T. Okamoto, K. Aino, T. Narihiro, H. Matsuyama, and I. Yumoto, World J. Microbiol. Biotechnol., 33, 70 (2017).

15. K. Hirota, M. Nishita, Z. Tu, H. Matsuyama, and I. Yumoto, Int. J. Syst. Evol. Microbiol., 68, 1123 (2018).

16. T. Ooi, T. Shibata, R. Sato, H. Ohno, H. S. Kinoshita, T. L. Thuoc, and S. Taguchi, Appl. Microbiol. Biotechnol., 75, 377 (2007).

17. S. Pricelius, C. Held, M. Murkovic, M. Bozic, V. Kokol, A. Cavaco-Paulo, and G. Guebitz, Appl. Microbiol. Biotechnol., 77, 321 (2007)

18. H. Suzuki, T. Abe, K. Doi, and T. Ohshima, Appl. Microbiol. Biotechnol., 102, 9171 (2018).

19. K. Yoneda, M. Yoshioka, H. Sakuraba, T. Araki, and T. Ohshima, Int. J. Biol. Macromol., 164, 3259 (2020).

20. M. Linhares, S. L. H. Rebelo, M. M. Q. Simões, A. M. S. Silva, M. G. P. M. S. Neves, J. A. S. Cavaleiro, and C. Freire, Appl. Catal., A, 470, 427 (2014).

21. P. Novotna, J. J. Boon, J. Horst, and V. Pacakova, Color. Technol., 119, 121 (2003).

22. V. Buscio, M. Crespi, and C. Gutiérrez-Bouzán, Materials, 7, 6184 (2014).

23. A. M. Bond, F. Marken, E. Hill, R. G. Compton, and H. Hügel, J. Chem. Soc., Perkin Trans. 2, 1735 (1997).

24. F. Govaert, E. Temmerman, and P. Kiekens, Anal. Chim. Acta, 385, 307 (1999).

25. E. Gasana, P. Westbroek, E. Temmerman, H. P. Thun, and P. Kiekens, Anal. Chim. Acta, 486, 73 (2003).

26. A. Vuorema, P. John, M. Keskitalo, and F. Marken, J. Appl. Electrochem., 38, $1683(2008)$

27. J. N. Etters, J. Soc. Dyers Colour., 109, 251 (1993).

28. P. A. Loach, Handbook of Biochemistry and Molecular Biology, Physical and Chemical Data, (Ed. G. D. Fasman), 3rd ed., Vol. 1, CRC, pp. 123-130 (1976).

29. P. A. Poels, B. W. Groen, and J. A. Duine, Eur. J. Biochem., 166, 575 (1987). 